University of Wollongong

Research Online

Faculty of Engineering - Papers (Archive)

Faculty of Engineering and Information

Sciences

April 2008

\title{
Dynamic Effect on Vibration Signatures of Cracks in Railway Prestressed Concrete Sleepers
}

Sakdirat Kaewunruen

Austrak Pty Ltd, sakdirat@hotmail.com

Alexander Remennikov

University of Wollongong, alexrem@uow.edu.au

Follow this and additional works at: https://ro.uow.edu.au/engpapers

Part of the Engineering Commons

https://ro.uow.edu.au/engpapers/416

\section{Recommended Citation}

Kaewunruen, Sakdirat and Remennikov, Alexander: Dynamic Effect on Vibration Signatures of Cracks in Railway Prestressed Concrete Sleepers 2008.

https://ro.uow.edu.au/engpapers/416

Research Online is the open access institutional repository for the University of Wollongong. For further information contact the UOW Library: research-pubs@uow.edu.au 


\title{
Dynamic Effect on Vibration Signatures of Cracks in Railway Prestressed Concrete Sleepers
}

\author{
Sakdirat Kaewunruen ${ }^{1,2, a}$ and Alex M Remennikov ${ }^{2, b}$ \\ ${ }^{1}$ Austrak Pty Ltd, Brisbane QLD 4105 Australia \\ ${ }^{2}$ University of Wollongong, Wollongong NSW 2522 Australia \\ a skaewunruen@austrak.com, ${ }^{\mathrm{b}}$ alexrem@uow.edu.au
}

\begin{abstract}
Keywords: Vibration characteristics, crack, railway prestressed concrete sleeper, experimental modal testing, structural health monitoring.
\end{abstract}

\begin{abstract}
In general, cracks in structural members indicate a level of serviceability of the engineering structures. Usually a hairline crack can be detected by visual inspection, crack gauge, fibre optical sensor, or laser sensor. Recently, an attempt to develop a non-destructive tool for health monitoring of prestressed concrete sleepers in railway tracks using the vibration responses has been established at the University of Wollongong, Australia. However, the fundamental understanding of the dynamic effect due to the cracks in sleepers is insufficient. This paper investigates the dynamic effect of the cracks on the vibration signatures of the railway prestressed concrete sleepers. The modal analysis has been used to evaluate the modal changes in vibration characteristics of the prestressed concrete sleepers in the frequency band between 0 and 1,600 Hz. The sample cracks have been initiated by the impulsive forces attributed to the high capacity drop impact testing machine. Comparison of the modal parameters of the intact and cracked sleepers has been highlighted in terms of natural frequencies and modal damping. This understanding will lead to further development of the economical technology to evaluate the structural integrity of railway track and its components.
\end{abstract}

\section{Introduction}

Ballasted railway track has become very common in rolling stock transportation and freight, especially in Australian coal and mining businesses. The Australian railway industry spent approximately 25-35 percent of its annual budget on rail track maintenance. The replacement costs of rails and sleepers were a considerable part of the expense [1]. In general, two major parts of ballasted railway track are the super-structure and the sub-structure. The super-structure is made up of steel rails, the fastening systems and sleepers; whilst the ballast, sub-ballast, sub-grade and formation, constitute the sub-structure. Figure 1 illustrates the ballasted track components. Esveld [2] notes that ballasted track has many advantages; for example, the construction costs are comparatively low, the maintenance and repair of track and its components are convenient, it has high damping and very good drainage properties, and noise can be controlled. Since railway track is always subjected to a variety of time-dependent loads, understanding the dynamic track behaviour is essential in order to evaluate the structural safety and service life of the railway track components.

Typically, sleepers are the track components resting on the ballast formation transversely as shown in Figure 1. Railway sleepers were first made in timber, and then a limited number of steel sleepers were used, followed by the now most-popular concrete sleepers. The majority and the trend of modern railway sleepers used worldwide are the prestressed concrete sleepers [3]. Due to the nature of dynamic loadings on railway track, the vibration characteristics of concrete sleepers are essential in analysis and design procedures. Also, to develop and validate a numerical simulation of rail track, the free vibration characteristics of the sleepers in various conditions are needed. Archives of vibration response measurements and parameters of sleepers can help engineers to identify the vibration-based damage or remotely monitor the sleeper health, since it is clear that some sleeper damages incur mostly at resonant frequencies of the sleepers [4]. The resonant 
vibrations of sleepers affect not only the sleepers themselves, but also the wheel-rail interaction forces. These effects have been analytically studied by Clark et al. [5], Grassie and Cox [6], and Knothe and Grassie [7]. Due to their wide use, the design and maintenance of prestressed concrete sleepers is a major concern to Australian track engineers.

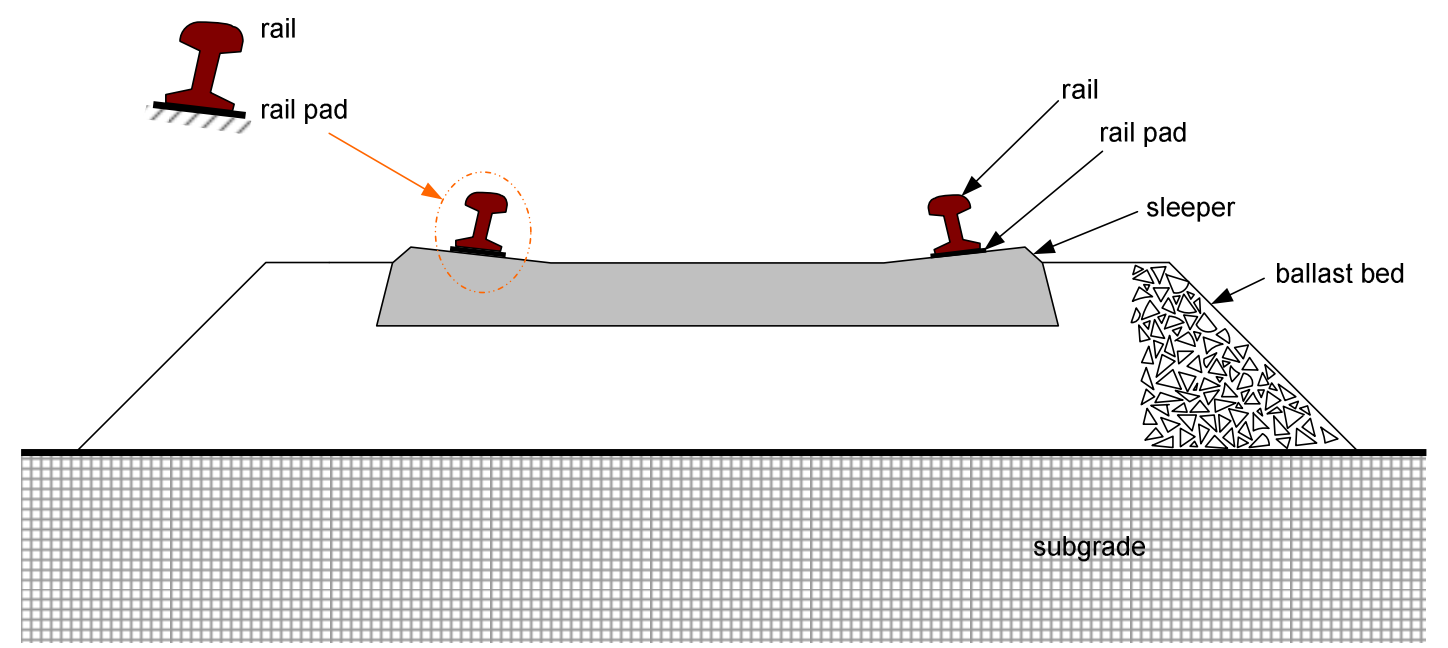

Fig.1 Typical ballasted track structure

There have been a number of studies related to the evaluation of dynamic properties of concrete sleepers. Experimental modal analysis is one of the widely used techniques to determine the vibration characteristics of concrete sleepers. Ford [8] performed modal analysis on a concrete sleeper in free-free condition using an electrodynamic shaker. Dahlberg and Nielsen [9] developed an analytical model for analysing dynamic behaviour of concrete sleepers in both free-free and insitu conditions. Based on some experimental results, a two-dimensional dynamic modelling for vibration analysis of concrete sleepers was done by Grassie [4]. It was found that the Timoshenko beam element was the best approximation of the concrete sleepers, even though the elastic properties of prestressed concrete sleepers may not be precise. Recently, Gustavson [10] and Vincent [11] performed the three-dimensional finite element modelling and modal testing of concrete sleepers in free-free condition. The results were in good agreement between numerical and experimental data. In reality, however, the sleepers are placed on ballast/subgrade formation. A comprehensive sleeper-ballast dynamic interaction has rarely been studied. Recently, the studies on rail pad parameters, improper ballast tamping, and the dynamic interaction between ballast and sleeper have been investigated [12-14]. However, the effect on imperfection of ballast and sleeper contact has yet been presented elsewhere.

This paper presents results of experimental modal analysis of both cracked and uncracked prestressed concrete sleepers in laboratory condition. Full-scale prestressed concrete sleepers were provided by an Australian manufacturer, Austrak. Impact hammer excitation technique has been used to evaluate the modal data over the frequency range of interest: 0 to 1,600 Hz. Frequency response functions (FRFs) were obtained using the Bruel\&Kjaer PULSE dynamic analyser. The FRFs were processed using the STAR Modal analysis package to identify natural frequencies and the corresponding mode shapes for the sleepers under the particular conditions. The conclusion highlights the effect of cracks on the dynamic properties of prestressed concrete sleepers, in terms of natural frequency change and damping variation. These results will help a development of an alternative method to determine the structural condition of concrete sleepers together with the normal inspection by railway organisations. 


\section{Analytical Modal Analysis}

Measurements of vibration responses in structures result in the modal parameter identification to obtain the dynamic characteristics of the structures. There are a number of methods to extract the dynamic characteristics, depending on the format of data obtained [15-16].

In a dynamic system, the equation of motion of the system can usually be represented by

$$
[M]\{\ddot{x}\}+[C]\{\dot{x}\}+[K]\{x\}=\{f\}
$$

where $[M]$ is the mass matrix, $[C]$ is the damping matrix, and $[K]$ is the stiffness matrix. The harmonic force applied to the system with magnitude $F$ and loading frequency $\omega$ is given by

$$
\{f\}=F \sin \omega t=F e^{j \omega t}
$$

The analytical solution can be contrived by Fourier Transform and can be found in [12].

\section{Experimental Modal Analysis}

All test specimens were prestressed concrete sleepers designed in accordance with AS1085.14-2003 [17]. The dimensions and masses of the test sleepers are tabulated in Table 1. The excitation points were located on the top surface of the sleeper at every $150 \mathrm{~mm}$ along the perimeter [12]. Based on previous experience, it was found that the number of these positions is ample to represent the vibration modes of interest. In this case, an accelerometer had a fixed position whilst an instrumented impact hammer was roved along the excitation points.

Table 1 Dimensions and masses of the test sleepers

\begin{tabular}{ccccccc}
\hline \multirow{2}{*}{$\begin{array}{l}\text { Mass } \\
(\mathrm{kg})\end{array}$} & $\begin{array}{c}\text { Gauge } \\
\text { Length }(\mathrm{m})\end{array}$ & $\begin{array}{c}\text { Total length } \\
(\mathrm{m})\end{array}$ & \multicolumn{2}{c}{ At railseat $(\mathrm{m})$} & \multicolumn{2}{c}{ At centre $(\mathrm{m})$} \\
\cline { 4 - 6 } & 1.60 & 2.85 & width & depth & width & depth \\
\hline 299.5 & 0.22 & 0.21 & 0.22 & 0.18 \\
\hline
\end{tabular}

Figure 3 shows the experimental setup of an uncracked sleeper on full-contact support. The support condition was simulated in laboratory according to AS1085.14 as an alternative material [18]. After performing the modal testing, the fresh sleeper was subjected to a severe impact load of $740 \mathrm{kN}$ at both rail seats and then retested. The magnitude of load is associated with the return period of 2,000 years, which is prescribed for 'very important' track structures [19]. The modal testing was performed again once the cracked sleepers were repeatedly given the impact loads for 50 times. The impact load tests were provided by the high-capacity drop-weight impact machine as shown in Figure 4. The instruments used in this study were a PCB accelerometer, the PCB impact hammer, and the Bruel\&Kjaer PULSE vibration analyser. It is important to note that the best position for mounting the accelerometer is at the end of the sleeper. The accelerometer was thus mounted at the sleeper end. Using the hammer to excite vibrations in the sleeper over the frequency range 0 to $1,600 \mathrm{~Hz}$, the 10-time average vibration responses represented by the FRFs were obtained using the PULSE system. Then, processing the recorded FRFs by STARModal, a modal analysis package, gave the natural frequencies and modal damping constants of the sleeper. All procedures were performed twice at each stage.

\section{Results and Discussion}

The results of modal testing for intact and cracked sleepers are illustrated in Tables 2. In this table, the first five modes of vibration are presented. For all conditions of the concrete sleepers, it was 
found that the first bending mode in a vertical plane clearly dominated the first resonant mode of vibration in either cracked or uncracked conditions. In addition, it is found for the uncracked sleeper that the second frequency is associated with the second bending mode, the third frequency with the lowest torsional mode, the fourth frequency with the third bending mode, and the fifth mode with the forth bending mode. Similar modes of vibration were identified for the cracked sleepers. Of all five modes, the most significant change in natural frequencies between the uncracked and cracked conditions was the first bending mode. The maximum frequency decrease was about 14 percent and 16 percent for the sleepers after 1 blow and 50 blows of impact, respectively. However, it was found that at higher resonant frequencies, the dynamic effect of cracks was decreased to about 4 to 7 percent difference in the forth and fifth vibration modes. Also, it should be noted that the cracks played a significant role in increasing the damping values of all flexural vibration modes. The maximum damping increase in the dynamic sleeper-ballast interaction was more than 50 percent in the first bending mode and the average change in other modes was between 10 and 40 percent. The mode shapes of ballasted sleepers were quite difficult to identify in that some mode shapes were sometimes too closely spaced between complex modes of vibration (e.g. Mode 5). Apparently, the cracks tend to have more significant influence on modal results corresponding to the flexural modes of vibration than those associated with the torsional modes. It should be noted that by degrees the dynamic softening phenomenon (natural frequency reduces as the amount of crack increases) prevails when cracks occur.

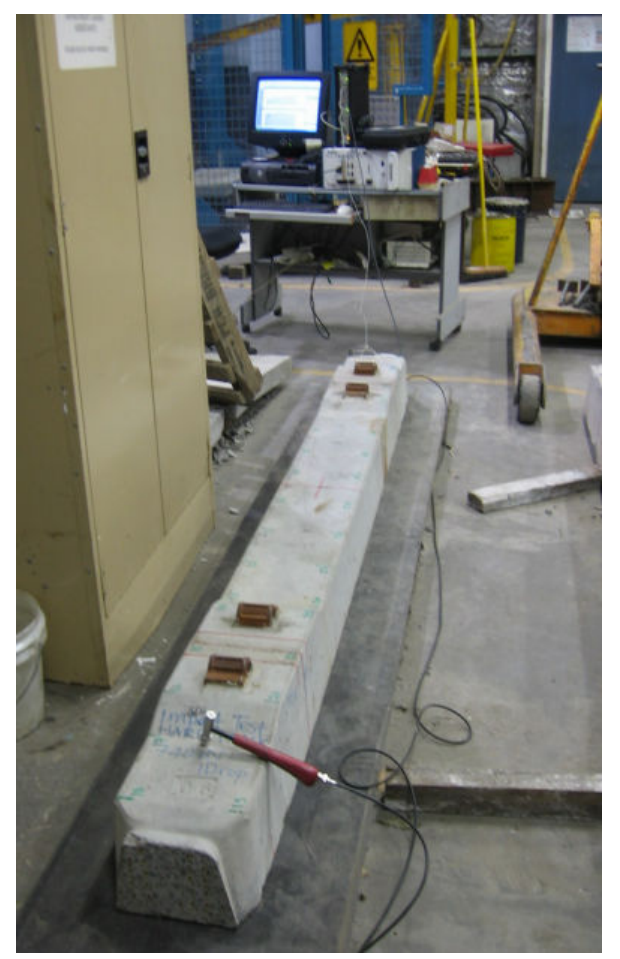

Fig. 3 Modal testing setup

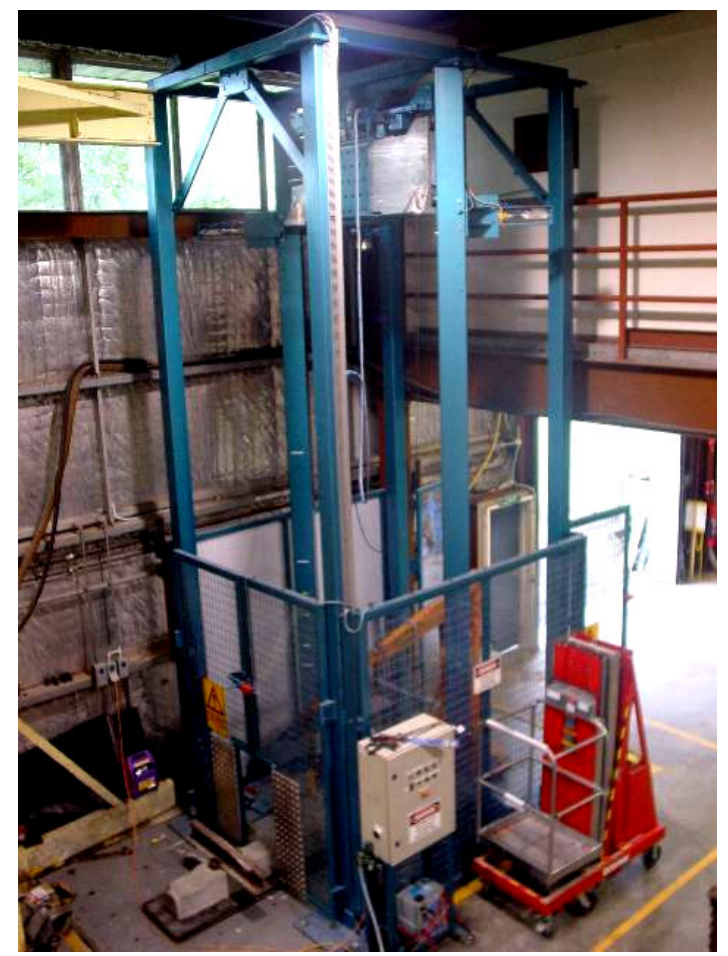

Fig.4 Impact testing facility

\section{Summary}

The experimental results of vibration characteristics of the prestressed concrete sleepers under different levels of structural serviceability are presented in this paper. The dynamic characteristics representing vibration signatures of the sleepers show the trend that cracks in concrete sleepers weaken their flexural stiffness, resulting in the decrease in resonant frequencies. In contrast, it has been evident in the experiments that the cracks develop internal frictions among cement, concrete, and aggregate so that the damping coefficients tend to increase with more crack incurrence. 


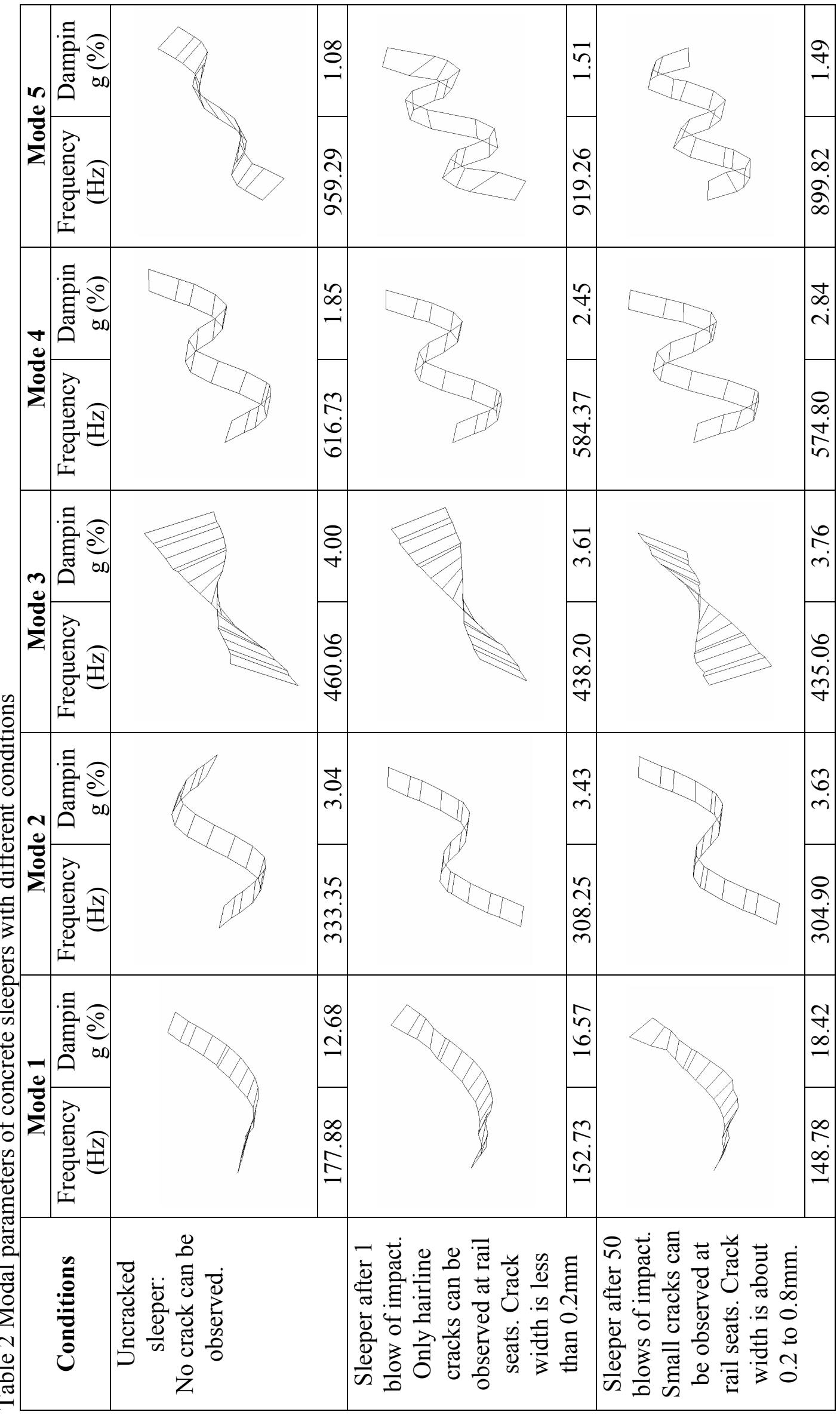




\section{Acknowledgement}

The authors are grateful to the Australian CRC for Railway Engineering and Technologies (RailCRC) for the financial support throughout the Project No 5/23. The prestressed concrete sleepers were kindly provided by Austrak and Rocla. The authors would also like to thank Alan Grant, Ian Bridge, Bob Roland, and Jason Knust, for their assistance during the course of this project.

\section{References}

[1] Yun WY and Ferreira L, Prediction of the demand of the railway sleepers: A simulation model for replacement strategies. Int J Product Econs; 81-82:589-595, (2003).

[2] Esveld C, Modern Railway Track, The Netherlands MRT Press, (2001).

[3] FIP Commission on Prefabrication, State of art report on concrete railway sleepers. London Thomas Telford, (1987).

[4] Grassie SL, Dynamic modelling of concrete railway sleepers. Journal of Sound and Vibration; 187(5):799-813, (1995).

[5] Clark RA, Dean PA, Elkins JA, and Newton SG, An investigation into the dynamic effects of railway vehicles running on corrugated rails. Journal of Mechanical Engineering Science; 24:65-76, (1982).

[6] Grassie SL and Cox SJ, The dynamic response of railway track with flexible sleepers to high frequency vertical excitation. Procs of Inst Mech Eng; 198D:117-124, (1984).

[7] Knothe K and Grassie SL, Modelling of railway track and vehicle/track interaction at high frequencies. Vehicle System Dynamics; 22:209-262, (1993)

[8] Ford R, Modal analysis of a concrete railway sleeper, Research Note AVG/RN881122-1, School of Mechanical and Industrial Engineering, UNSW, Australia, (1988)

[9] Dahlberg T and Nielsen J, Dynamic behaviour of free-free and in-situ concrete railway sleepers. Procs of Int Symp on Precast Concrete Railway Sleepers, Madrid, Spain, (1991, April).

[10] Gustavson R, Static and dynamic finite element analyses of concrete sleepers. Licentiate Eng. Thesis, Dept of Struct Eng, Chalmers University of Technology, Göteborg, Sweden, (2000).

[11] Vincent G, Modal analysis and numerical modeling of a concrete railway sleepers. M.Eng. Thesis, Dept of Struct Eng, Chalmers University of Technology, Göteborg, Sweden, (2001).

[12] Remennikov, AM and Kaewunruen, S, "Experimental investigation on dynamic railway sleeper/ballast interaction." Experimental Mechanics, 46(1), 57-66, (2006).

[13] Kaewunruen, S and Remennikov, AM, "Sensitivity analysis of free vibration characteristics of an in-situ railway concrete sleeper to variations of rail pad parameters." Journal of Sound and Vibration, 298(1-2), 453-461, (2006).

[14] Kaewunruen, S and Remennikov, AM, "Effect of improper ballast tamping/packing on dynamic behaviors of on-track railway concrete sleeper." International Journal of Structural Stability and Dynamics, 7(1), 1-11, (2007).

[15] Ewins DJ, Modal Testing: Theory and Practice, Taunton Research Studies Press, (1995).

[16] He H and Fu Z, Modal Analysis, Great Britain Butterworth - Heinemann Publishers, (2001). 
[17] Standards Australia, "Railway track material - Part 14: Prestressed concrete sleepers" Australian Standard: AS1085.14-2003, (2003).

[18] Kaewunruen, S. and Remennikov, AM, "Experimental simulation of railway ballast in laboratory and its verification by modal testing." Experimental Techniques, (2007), inpress.

[19] Murray M and Cai Z, Literature review on the design of railway prestressed concrete sleeper. RSTA Research Report, Australia, (1998).

Note: The authors' work can be electronically found via the University of Wollongong's Research Online at URL http://ro.uow.edu.au 